\title{
TRANSFORMASI DALAM PERFORMA PESAWAT TERBANG DI GENERASI BERBEDA
}

\author{
Diachirta Chrisna Ayu Dwiharpini ${ }^{1}$, Michael F.J. Saputra ${ }^{2}$ Muhammad Daffa Aly $^{3}$ \\ Program Studi Teknik Mesin, Universitas Pembangunan Nasional "Veteran" Jakarta, Jakarta Selatan 123 \\ email $^{1}$ : diachirta.harpini@gmail.com
}

\begin{abstract}
Much people know that the fighter only just defense and security when wars in the air. Then, dont know that the fighters had many generation and each generation have a different. Because of that, we will tells to the reader that transformation of the fighter performance in different generation have advantages and disadvantages in the performances. With the comparation that we built, so we know which are the biggest performance.
\end{abstract}

Keywords: performance, fighter, part of fighter

\section{PENDAHULUAN}

Seiring berkembangnya zaman, teknologi juga mengalami perkembangan yang pesat pula. Adanya kemajuan di bidang teknologi semakin memudahkan manusia untuk melakukan aktifitasnya sehari-hari. Salah satu teknologi yang mengalami perkembangan pesat adalah teknologi di bidang penerbangan. Saat ini kita sudah bisa menikmati kecanggihan teknologi di bidang penerbangan.

Penemuan pesawat terbang merupakan fenomena sejarah yang penting, baik dalam hal penggunaan untuk tujuan-tujuan damai maupun perang. Hanya dalam tempo puluhan tahun sesudah itu, pesawat terbang telah membuat dunia kita begitu sempit, bahkan ruang angkasa pun rasanya dapat disentuh jari. Dan lebih dari itu, penemuan pesawat terbang bermuatan manusia merupakan pemula dan pembuka jalan bagi penerbangan di luar angkasa.

Di dalam sebuah Negara, keamanan dan pertahanan merupakan suatu modal kekuatan bagi Negara untuk menunjukan bagaimana sebuah negara memiliki potensi dan kualitas yang bagus dalam bersaing. Oleh karena itu, pesawat tempur pun menjadi salah satu contoh dalam bidang pertahanan dan keamanan suatu negara khususnya dalam bidang teknologi yang sudah canggih di era modern seperti saat ini.

\section{TINJAUAN PUSTAKA}

\section{Cara Kerja Pesawat Dapat Terbang}

Pesawat bisa terbang karena ada momentum dari dorongan horizontal mesin pesawat
(Engine), kemudian dorongan engine tersebut akan menimbulkan perbedaan kecepatan aliran udara dibawah dan diatas sayap pesawat. Kecepatan udara diatas sayap akan lebih besar dari dibawah sayap di karenakan jarak tempuh lapisan udara yang mengalir di atas sayap lebih besar dari pada jarak tempuh di bawah sayap, waktu tempuh lapisan udara yang melalui atas sayap dan di bawah sayap adalah sama . Menurut hukum Bernoulli, kecepatan udara besar menimbulkan tekanan udara yang kecil . sehingga tekanan udara di bawah sayap menjadi lebih besar dari sayap pesawat bagian atas. Sehingga akan timbul gaya angkat (Lift) yang menjadikan pesawat itu bisa terbang,

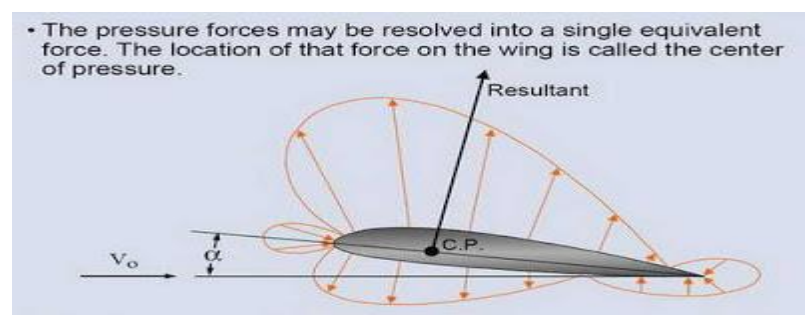

Gambar 1

Hukum Bernoulli tentang aliran dan tekanan udara ( sumber : http://www.edukasi.net)

Pesawat terbang dapat terangkat ke udara karena kelajuan udara yang melalui sayap pesawat tersebut, berbeda dengan roket yang terangkat ke atas karena aksi-reaksi antara gas yang disemburkan roket dengan roket itu sendiri. 
Roket menyemburkan gas ke belakang (ke bawah), sebagai reaksinya gas mendorong roket ke atas. Jadi roket tetap dapat terangkat ke atas meskipun tidak ada udara, pesawat terbang tidak dapat terangkat jika tidak ada udara.Penampang sayap pesawat terbang mempunyai bagian belakang yang lebih tajam dari pada bagian depan, dan sisi bagian atas yang lebih melengkung dari pada sisi bagian bawahnya. Gambar di bawah adalah bentuk penampang sayap yang disebut dengan aerofoil

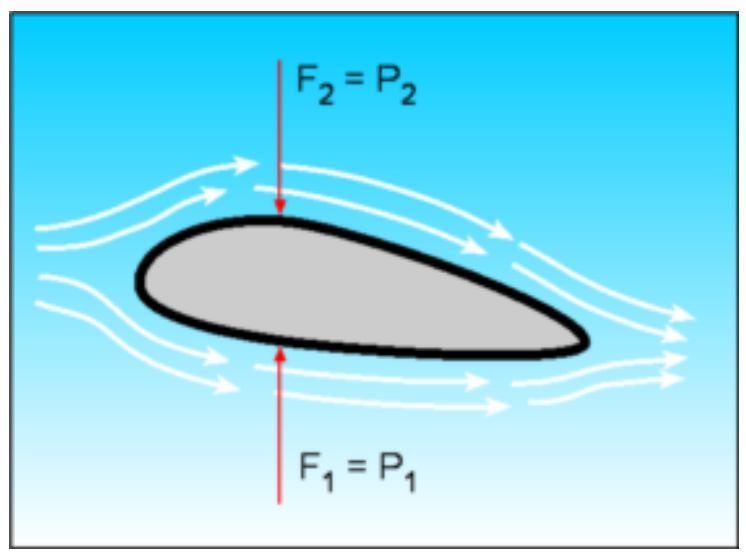

Gambar 2

Garis arus pada sisi bagaian atas lebih rapat daripada sisi bagian bawahnya, yang berarti laju aliran udara pada sisi bagian atas pesawat (v2) lebih besar daripada sisi bagian bawah sayap (v1). Sesuai dengan asas Bernoulli ;

$$
p_{1}+\frac{\mathbf{1}}{\mathbf{2}} \boldsymbol{\rho}_{1} v_{1}^{2}+\boldsymbol{\rho} g h_{1}=p_{2}+\frac{\mathbf{1}}{\mathbf{2}} \boldsymbol{\rho}_{2} v_{2}^{2}
$$

Tekanan pada sisi bagian atas pesawat (p2) lebih kecil daripada sisi bagian bawah pesawat (p1) karena laju udara lebih besar. Beda tekanan p1 p2 menghasilkan gaya angkat sebesar: F1-F2 = (p1-p2)A,

dengan A merupakan luas penampang total sayap jika nilai p1 - p2 dari persamaan gaya angkat diperoleh ;

$$
F_{1}-F_{2}=\frac{1}{2} \rho\left(v_{2}^{2}-v_{1}^{2}\right) A
$$

dengan $\rho$ adalah massa jenis udara. Pesawat dapat terangkat keatas jika gaya angkat lebih besar daripada berat pesawat, jadi apakah suatu pesawat dapat atau tidak tergantung pada berat pesawat, kelajuan pesawat dan ukuran sayapnya. Makin besar kecepatan pesawat, makin besar kecepatan udara dan ini berarti<smiles>[Y10][Y]</smiles>

bertambah besar sehingga gaya angkat ( F1-F2 > mg ), Jika pesawat telah berada pada ketinggian tertentu dan pilot ingin mempertahankan ketinggiannya (melayang di udara), maka kelajuan pesawat harus diatur sedemikian rupa sehingga gaya angkat sama dengan berat pesawat $(\mathrm{F} 1-\mathrm{F} 2=\mathrm{mg})$.

\section{Penerapan Hukum Bernoulli untuk mendesain pesawat terbang}

Pesawat terbang dirancang sedemikian rupa sehingga hambatan udaranya sekecil mungkin. Pesawat pada saat terbang akan menghadapi beberapa hambatan, diantaranya hambatan udara, hambatan karena berat badan pesawat itu sendiri, dan hambatan pada saat menabrak awan. Setelah dilakukan perhitungan dan rancangan yang akurat dan teliti, langkah selanjutnya adalah pemilihan mesin penggerak pesawat yang mampu mengangkat dan mendorong badan pesawat.Pada dasarnya, ada empat buah gaya yang bekerja pada sebuah pesawat terbang yang sedang mengangkasa.

(1).Berat pesawat yang disebabkan oleh gaya gravitasi

bumi.

(2).Gaya angkat yang disebabkan oleh bentuk pesawat.

(3).Gaya ke depan yang disebabkan oleh dorongan mesin / engine (3).Gaya hambatan yang disebabkan oleh gesekan udara

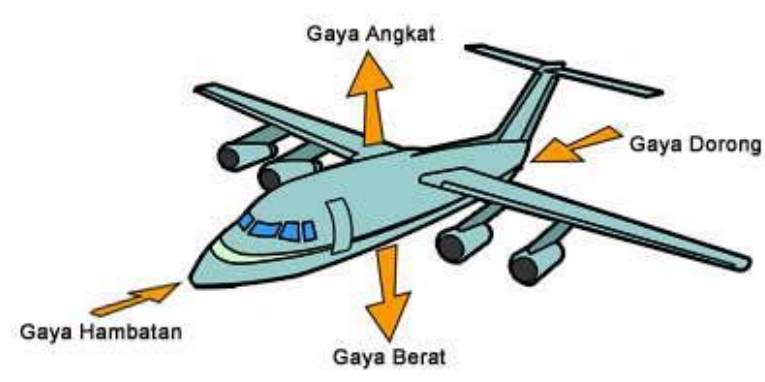

Gambar 3

Jika pesawat hendak bergerak mendatar dengan suatu percepatan, maka gaya ke depan harus lebih besar daripada gaya hambatan dan gaya 
angkat harus sama dengan berat pesawat. Jika pesawat hendak menambah ketinggian yang tetap, maka resultan gaya mendatar dan gaya vertical harus sama dengan nol. Ini berarti bahwa gaya ke depan sama dengan gaya hambatan dan gaya angkat sama dengan berat pesawat

\section{Pesawat Tempur}

Pesawat tempur, pesawat yang digunakan saat perang diudara. Pada umumnya pesawat tempur memiliki bentuk yang ramping, dapat bergerak lincah, dan diperlengkapi dengan persenjataan yang lengkap didalamnya. Pesawat tempur terbagi menjadi bagan-bagian pesawat, jenis mesin pesawat, dan bahan bakar pesawat. Bagian-bagian pesawat yaitu bagian depan, sayap dan badan pesawat, ekor, dan persenjataan. Jenis mesin pesawat tempur yang dipakai yaitu mesin turbofan. Bahan bakar pesawat tempur memakai Avtur.

\section{Fungsi Pesawat Tempur}

Pesawat Tempur memiliki fungsi yaitu sebagai pertahanan dan pertempuran yang dilakukan di udara, pesawat tempur ini dituntut untuk dapat melakukan manuver secara lincah dan cepat.

\section{Macam-macamPesawatTempur}

\section{A. Generasi 4}

\section{Saab JAS 39 Gripen}

Saab JAS 39 Gripen adalah pesawat tempur multirole (multiperan), yaitu untuk misi penyerangan udara-ke-udara, udara-kepermukaan dan misi pengintaian. Konfigurasi sayap delta canard-nya menjadikan Gripen sebagai pesawat gesit untuk skenario pertempuran jarak dekat. Gripen yang pertama dioperasikan oleh Angkatan Udara Swedia pada tahun 1997. Hingga saat ini, selain Swedia (produsen) yang tercatat menggunakannya adalah Republik Ceko, Hongaria, Afrika Selatan dan Thailand. Gripen beraksi pada tahun 2011 di Libya untuk mendukung Operasi Unified Protector (pembebasan Libya). Gripen E, versi baru dari Gripen C/D dapat dipersenjatai dengan rudal METEOR, AMRAAM, IRIS-T, dan AIM-9. Menggabungkan peralatan multifrekuensi data, sistem avionik terintegrasi, sensor fusi dan radar multimode PS05 jarak jauh.

\section{Eurofighter Typhoon}

Eurofighter Typhoon termasuk pesawat tempur multirole baru yang dianggap sebagai salah satu yang terbaik di dunia. Bersayap delta plus integrasi avionik dan sensor modern, Defensive Aids Sub System (DASS) dan senjata seperti kanon Mauser BK-27 27mm, rudal udarake-udara, udara-ke-darat, rudal anti-kapal dan amunisi precision-guided.

Eurofighter Typhoon dikembangkan dari hasil kolaborasi multinasional militer-militer di Eropa yang dikomandoi oleh NATO Eurofighter dan Tornado Management Agency (NETMA). Program ini telah mengantarkan industri pertahanan Eropa ke teknologi terdepan. Sepintas pesawat ini mirip dengan Gripen, namun salah satu pembedanya adalah pada bagian knalpot (Typhoon 2 mesin, Gripen 1 mesin). Debut pertama Eurofighter Typhoon terjadi pada 2011, kala itu digunakan untuk misi pengintaian dan penyerangan di Libya oleh Angkatan Udara Kerajaan Inggris (RAF) dan Angkatan Udara Italia.

\section{Dassault Rafale}

Digambarkan sebagai pesawat tempur "omnirole" (beberapa misi dalam waktu yang sama) oleh produsennya yaitu Dassault Aviation. Rafale menggunakan mesin ganda dan sebagai pesawat multirole (sebut saja multirole) yang mampu melaksanakan tugas menjaga kedaulatan negara, serangan (deep/dalam), pengintaian dan misi udara untuk menangkal nuklir.

Pesawat ini dioperasikan oleh Angkatan Udara dan Angkatan Laut Perancis. Pesawat ini dilengkapi dengan avionik terbaru dan sistem sensor cerdas. Mampu menembakkan kanon 30 mm, rudal udara-ke-udara dan rudal udara-kepermukaan, rudal anti-kapal, serta berbagai bom laser-guided dan amunisi untuk serangan darat.

Aksi pertama Rafale terjadi pada tahun 2002 saat Operasi Enduring Freedom (Afghanistan), lalu Libya dan baru-baru ini dalam Operasi Serval (Mali). Pesawat ini terseda dalam tiga varian, yaitu Rafale C (kursi tunggal), Rafale B (kursi ganda) dan Rafale M varian kapal induk (satu kursi).

\section{Lockheed Martin F-16 Fighting Falcon}

F-16 Fighting Falcon menggunakan mesin tunggal dan kemampuan tempurnya sudah terbukti. Awalnya masterpiece ini dirancang oleh 
General Dynamics AS untuk digunakan dalam misi superioritas udara bagi Angkatan Udara AS. Kemudian seiring waktu F-16 berevolusi menjadi pesawat multirole dengan memasukkan teknologi terbaru.

F-16 adalah pesawat tempur yang memiliki tingkat kesuksesan tinggi di 26 negara yang memilikinya, setidaknya sudah 4.500 unit yang dibuat dan ada 54 unit pesanan untuk 15 negara pemesan. Pesawat tempur ini menjalankan aksinya saat Operasi Badai Gurun di Irak tahun 1991, selanjutnya Perang Irak II, Afghanistan dan libya. Versi F-16 terbaru yaitu, Blok 50/52 dan Blok 60 menggunakan teknologi modern dan upgrade berdasarkan pengalaman tempur selama ini, antara lain avionik, kokpit dan instrumen pilot friendly, sensor dan paket senjata terbaik.

\section{Boeing F-15E Strike Eagle}

F- 15E Strike Eagle termasuk pesawat tempur multirole yang superior dibanding pesawat generasi 4 lain. F-15E Strike Eagle dikembangkan sebagai turunan dari pesawat sebelumnya yaitu F-15A/D. Untuk saat ini, F$15 \mathrm{E}$ menjadi tulang punggung kekuatan Angkatan Udara AS.

F-15E bisa membawa amunisi Joint Direct Attack Munition (JDAM), sistem senjata AGM130 Standoff, rudal udara-ke-udara jarak menengah AIM-120, AIM-9x Sidewinder dan berbagai jenis bom. Pesawat ini dapat terbang hingga dua kali kecepatan suara.

Sisi avioniknya menjadikan pesawat ini mampu melaksanakan serangan udara-ke-udara dan udara-ke-darat di semua kondisi cuaca baik itu siang maupun malam hari.

F-15E secara ekstensif digunakan dalam Operasi Desert Shield dan Desert Storm serta Operasi Southern Watch dan Northern Watch. Aksi tempur lainnya yaitu saat Operasi Deny Flight, Operasi Enduring Freedom, Operasi Iraqi Freedom dan Operasi Odyssey Dawn.

\section{Su-30MKI (Flanker-H)}

Su-30 adalah pesawat multirole jarak jauh dua kursi yang dirancang oleh Sukhoi Rusia. Dari seluruh varian Su-30, yang diyakini terbaik adalah Su-30MKI yang saat ini digunakan oleh Angkatan Udara India. Sudah diproduksi sendiri oleh India melalui India Hindustan Aeronautics Limited (HAL) di bawah lisensi Rusia.
Su-30MKI pertama kali dioperasikan IAF pada tahun 2002, sedangkan Su-30MKI pertama buatan India baru diperkenalkan pada tahun 2004.

Su-30MKI mampu membawa berbagai rudal udara-ke-udara dan rudal udara-ke-darat, termasuk rudal jelajah supersonik BrahMos, juga senjata GSH-30-1 $30 \mathrm{~mm}$ dan berbagai bom.

\section{Boeing F/A-18E/F Super Hornet}

F/A-18E/F Super Hornet juga pesawat tempur multirole. Varian ini adalah desain ulang/perubahan besar dari pesawat sebelumnya yaitu F/A-18C/D Hornet. Super Hornet saat ini digunakan oleh Angkatan Laut AS dan Angkatan Udara Australia (RAAF).

Angkatan Laut AS mengoperasikan pesawat ini mulai tahun 1999 untuk menggantikan pesawat tempur Grumman F-14 Tomcat. F/A-18F Super Hornet (versi dua kursi) dioperasikan RAAF pada tahun 2010.

Kemampuan pesawat tempur ini terbukti saat Operasi Pembebasan Irak, Operasi Enduring Freedom, Operasi Southern Watch dan perang di Afghanistan.

Sistem jaringan Super Hornet yang terintegrasi meningkatkan interopabilitas dan dukungan total baik untuk pilot dan tentara di lapangan. Sebelas (11) hard-point pada Super Hornet dapat menampung berbagai senjata campuran, antara lain senjata untuk serangan udara-ke-udara dan udara-ke-darat, serta berbagai amunisi cerdas, termasuk laser-guided bombs.

\section{Sukhoi Su-35}

Sukhoi Su-35 adalah varian kelas berat dari pesawat tempur versi Su-27. Su-35 dianggap sebagai pesawat generasi $4++$ karena sebagian menggunakan teknologi generasi kelima. Teknologi mutakhirnya membuatnya menjadi yang paling unggul dari semua pesawat tempur generasi keempat lainnya, baik pesawat yang masih dikembangkan saat ini di dunia.

Prototipe pertama Su-35 dibangun di Komsomolsk-na-Amure Aviation Production Association pada tahun 2007. Penerbangan perdananya terjadi pada bulan Februari 2008.

Su-35 mampu menyebarkan rudal udara-keudara jarak pendek dan jarak jauh, amunisi udara-ke-darat terarah dan presisi yaitu rudal, bom dan roket. Empat belas (14) hard-point pada 
Su-35 menjadikannya mampu membawa muatan senjata hingga 8 ton.

\section{B. Generasi 5 \\ 1. HAL AMCA (India)}

Pesawat ini adalah pesawat siluman multiperan yang sedang dikembangkan oleh India. Advanced Medium Combat Aircraft (AMCA) saat ini sedang dirancang dan dikembangkan oleh Defence Research and Development Organization (DRDO) India, serta direncanakan akan siap digunakan pada 2018. Pesawat ini nantinya akan melengkapi HAL Tejas, HAL FGFA, Su-30MKI, dan Dassault Rafale sebagai kekuatan tempur angkatan udara India.

\section{Shenyang J-31 (China)}

Shenyang J-31 adalah pesawat generasi kelima buatan China. Jet tempur ukuran sedang yang diprediksi akan diberi nama Gyrfalcon atau Falcon Hawk ini dikembangkan oleh Shenyang Aircraft Corporation. Pesawat yang juga disebut sebagai F60 atau J-21 Snowy Owl ini telah terbang dalam sebuah uji coba pada 31 Oktober 2012.

\section{HAL Sukhoi PMF/FGFA (India)}

Pesawat India kedua dalam daftar ini. HAL Sukhoi PMF/FGA adalah jet tempur yang dikembangkan oleh India dan Rusia. Pesawat ini adalah turunan dari Sukhoi T-50 PAK FA yang diperuntukkan bagi angkatan udara India. Rencananya, versi lengkap PMF FA akan memiliki 43 perbaikan dari versi T-50 termasuk stealh supercruise, sensor yang lebih baik, dan perangkat pertempuran. PMF FA telah melakukan uji coba pada 2014 dan direncanakan siap pada 2022.

\section{TAI TFX / F-X (Turki)}

Turki tidak mau kalah dalam pengembangan teknologi militernya. Setelah bertahun-tahun menggunakan teknologi militer asing, Turkish Aerospace Industri (TAI) akhirnya mengembangkan TFX, sebuah jet tempur generasi kelima. Tidak banyak yang diketahui mengenai pesawat ini, namun, Turki dikabarkan berkomitmen dalam pengembangan pesawat ini.

\section{Mitsubishi ATD-X Shinshin (Jepang)}

Mitsubishi ATD-X adalah purwarupa jet tempur generasi kelima dengan teknologi siluman. Pesawat berkode Shinshin ini tengah dikembangkan oleh Departemen Technical Research and Development Institute (TRDI) Kementerian Pertahanan Jepang, dengan Mitsubishi Heavy Industries sebagai kontraktor utamanya.

\section{KAI KF-X (Korea Selatan)}

Pesawat tempur multiperan generasi kelima ini adalah program kerjasama antara angkatan udara Korea Selatan (ROKAF) dengan angkatan udara Indonesia (TNI-AU), sebagai rekan utamanya. Tidak banyak data mengenai pesawat ini selain kemampuannya yang direncanakan melebihi pesawat tempur generasi keempat dengan kemampuan stealth, mesin kelas atas, dan kemampuan manuver yang lincah.

\section{Lockheed Martin F-35 Lightning II (AS)}

F-35 Lightning II adalah pesawat joint strike force yang dapat digunakan untuk berbagai keadaan. Pesawat ini dikabarkan dilengkapi dengan teknologi siluman, dengan berbagai keunggulan sistem komputer. Dibuat dalam tiga varian, F35A adalah pesawat yang lepas landas secara konvensional dari landasan pacu, F35B dilengkapi kemampuan lepas landas secara vertikal, dan F35C dirancang untuk digunakan di kapal induk.

\section{Sukhoi T-50 PAK FA (Rusia)}

Digembar gemborkan sebagai pesawat tercanggih Rusia, Sukhoi T-50 PAK FA diprediksi akan menggantikan MiG-29 dan Su-27 sebagai kekuatan utama armada angkasa Rusia. Pesawat yang dikembangkan oleh angkatan udara Rusia ini dilengkapi dengan teknologi stealth dan menjadi awal mula dari Sukhoi/HAL FGFA yang dikembangkan India. PAK FA telah melakukan penerbangan perdana dalam uji coba 29 Januari 2010.

\section{Chengdu J-20 (China)}

Diproduksi oleh Chengdu Aircraft Industry, Chengdu J-20 adalah pesawat multiperan generasi kelima berteknologi siluman yang dibuat untuk angkatan udara China. Setelah melakukan penerbangan perdana pada uji coba 11 Januari 2011, pesawat berjuluk Black Eagle ini direncanakan akan beroperasi pada 2017-2019.

\section{Lockheed Martin F-22 Raptor (AS)}

Beroperasi sejak 2005, F-22 adalah pesawat generasi kelima pertama milik angkatan udara AS (USAF). Pesawat ini telah dilengkapi dengan teknologi siluman dan dirancang untuk memenangkan pertempuran udara. F-22 juga digunakan dalam berbagai fungsi lainnya seperti serangan terhadap target di darat, mencegat sinyal dan mengurangi kemampuan radar lawan. Meski begitu, pesawat ini tidak lagi diproduksi karena mahalnya biaya pembuatan dan kemunculan F-35 yang diprediksi lebih serbaguna dan seharusnya lebih murah. F-22 terakhir dikirimkan ke USAF pada 2012. 


\section{METODE PENELITIAN}

\section{A. Bagian-BagianPesawat Tempur}

\section{A.1. PesawatBagianDepan}

\section{1) Canard}

Secara performa, carnard memberikan manuver yang lebih karena bentuknya yang runcing, akan tetapi canard yang berbentuk runcing memberikan kekurangan terhadap pesawat tempur karena membuat pesawat tempur mudah terdeteksi akibat pantulan gelombang yang dikirim oleh transimitter.

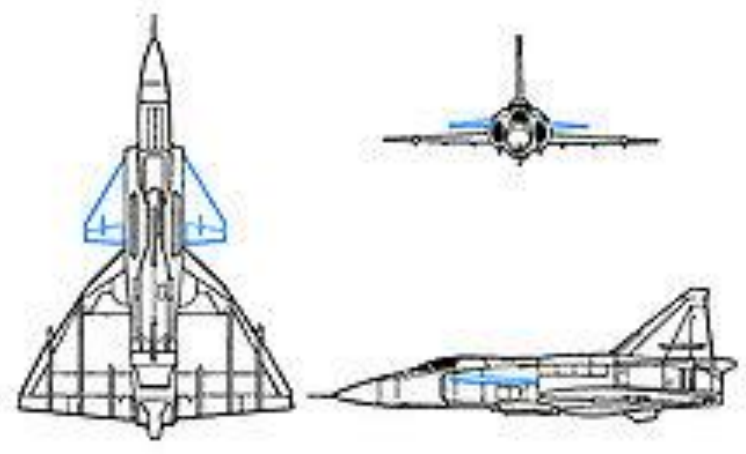

Gambar 4

2) Forebody Fuselage

Fungsi dari Forebody ini untuk melakukan manuver yang sangat tajam

\section{3) Duct Path Air Inlet}

Merupakan tempat yang dilalui udara saat akan masuk ke mesin (air inlet)

\section{A.2. SayapdanBadanPesawat}

Seluruh generasi 4 dan 5 menggunakan konfigurasi sayap delta. Dari segi aerodinamis, sayap delta memberikan keuntungan manuver. Sedangkan dari strukturnya, sayap delta lebih kuat dan kaku saat pesawat melakukan manuver, disamping keuntungan manufakturnya yang lebih sederhana.

Sayap delta juga memiliki karakteristik yang baik, sudut yang bias dicapai sayap delta mencapai $35^{\circ}$. Oleh karena itu, sayap delta sangat cocok digunakan untuk pesawat tempur. Bentuk sayap yang menyatu dengan badan pesawat disebut dengan blended wing body. Permukaan pesawat terlihat lebih rapi tanpa banyak lekukan yang diakibatkan karena bentuk sayap dan badan pesawat. Blended wing body bertujuan untuk memberikan manuver dan aerodinamika yang baik serta mampu mereduksi Radar Cross Section.

\section{A.3. Ekor}

Konfigurasi ekor meliputi horizontal tailplane (HTP) dan vertical tailplane (VTP).

\section{A.4. Persenjataan}

Banyak sekali senjata yang dipakai dalam pesawat tempur contohnya yaitu rudal dengan berbagai macam jenisnya, ada juga yang membawa bom didalamnya dan lain sebagainya. Persenjataan ini ada yang disimpan diluar dan ada pula yang tersembunyi didalam pesawat.

\section{Mesin}

Mesin yang dipakai oleh pesawat tempur yaitu mesin turbofan, turbofan merupakan turunan mesin turbojet, komponennya yaitu kipas, kompresor, ruangbakar, turbin, mixer, nozzle.

Prinsip kerja turbofan, udara masuk kedalam blade (low pressure compressor) dan dikompres oleh blade yang lebih kecil ukurannya (high pressure compressor), masuk keruang pembakaran dan diberi ignition sampai suhu dan temperaur tinggi setelah itu disemprot oleh bahan bakar. Karena terjadi pembakaran maka berubahlah energi kimia menjadi energi dorong. Energi dorong yang dihasilkan ini mendorong turbin dengan tekanan tinggi, turbin ini terhubung langsung dengan compressor bertekanan tinggi sehngga kompresor beretekanan tingi tersebut dapat berputar kembali. Energi dorong tersebut juga mendorong turbin bertekanan rendah yang terhubung langsung dengan kompresor bertekanan rendah, dan sisanya merupakan tenaga dorong pesawat.

Jadi prinsip kerja turbofan dapat disederhakan sebagai berikut, turbofan melakukan beberapa step tetapi hanya dalam satu waktu, berbeda dengan motor bakar yang mempunyai 4 step atau 2 step.

Kelebihan mesin turbofan adalah lebih efisien dari segi tenaga yang dihasilkan gaya dorong yang dihasilkan bukan hanya dari pembakaran tetapi juga dari udara yang di bypass pada engine atau bias dibilang bahwa udara di bypass tidak ikut terbakar dalam ruang pembakaran Karena udara tersebut melewati jalur tersendiri dan langsung menuju nozzle. Terdapat dua bypass yaitu low bypass ratio dan high bypass ratio, low bypass ratio digunakan untuk pesawat tempur sedangkan high bypass ratio digunakan untuk pesawat komersial.

\section{Bahan Bakar}

Avtur, Aviation Turbine Fuel atau Avtur yang secara international lebih dikenal dengan nama Jet A-1 adalah bahan bakar yang digunakan untuk pesawat terbang jenis jet atau turbo jet, baik tipe jet propulsion atau propeller. Berbeda dengan Avgas yang diolah dari bensin, Avtur diolah dari kerosene (minyak tanah) yang digunakan untuk keperluan penerbangan sipil di seluruh dunia. Kalian tahu minyak tanah yang dipakai untuk memasak atau untuk lampu teplok? Itulah asalnya Avtur. Perbedaannya terletak pada segi kebersihan, titik didih dan flash pointnya 


\section{HASIL DAN PEMBAHASAN}

Pada penelitian kali ini akan membandingkan tentang pesawat tempur dengan jenis F-16 (Fighting Falcon) dan Sukhoi PAK-FA T-50

1) F-16 fighting Falcon dan sukhoi PAK-FA T50 tidak membutuhkamn bagian canard dikarenakan canard menyebabkan navigasi pesawat mudah terdeteksi oleh pesawat lain. Namun jika terdapat adanya canard dapat memberikan kelebihan manouver dalam segi performa

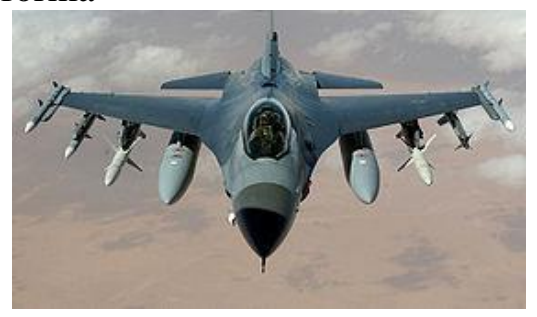

Gambar 5

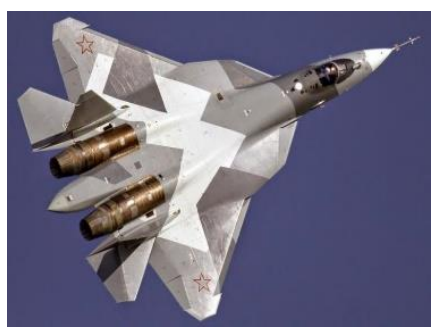

Gambar 6

2) Untuk bagian forebody fuselage F-16 Fighting Falcon belum terbentuk chine, sedangkan untuk sukhoi PAK-FA T-50 sudah berbentuk chine type cross selection. Dengan bertujuan untuk menciptakan vortex, semakin lancip sudut bagian depan pesawat maka vortex yang dihasilkanakan semakin kuat dan kokoh. Selain itu adanya perancangan leading edge extension dengan sudut tertentu yang dimaksudkan agar pesawat tempur dapat melakukan maneuver yang maksimal hingga 25 derajat.

3)

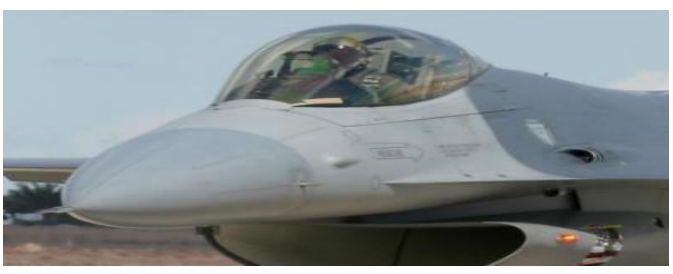

Gambar 7

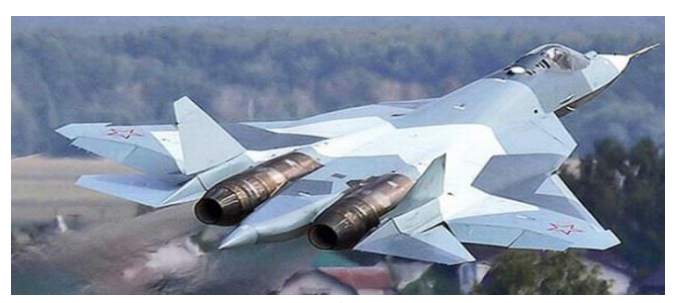

Gambar 8
4) Untuk bagian duct path air inlet pada F-16 fighting falcon masih ada yang berbentuk persegi dan ada pula berbentuk bulat serta arah lengkungannya masih cenderung lurus menuju engine. Sedangkan untuk sukhoi PAK-FA T-50 bentuk intakenya dibuat seperti jajar genjang dan air inlet sitemnya dibuat melengkung agar engine compressor tidak terlihat dari luar. Dengan bertujuan untuk mereduksi radar cross selection (RCS) karena jika gelombang radar lawan mengenai fan compressor yang berputar, maka gelombang tersebut akan terpantul kuat menuju transmitter-nya, namun jika duct tersebut dibuat melengkung dan mesinnya tidak terlihat, maka gelombang radar akan mengenai dinding dan terpantul lemah menuju transmitter-nya. Perancangan duct yang seperti ini juga mempunyai kerugian, yaitu thrust yang dihasilkan akan berkurang, selain itu pembuatan duct path yang melengkung akan membutuhkan banyak ruang.

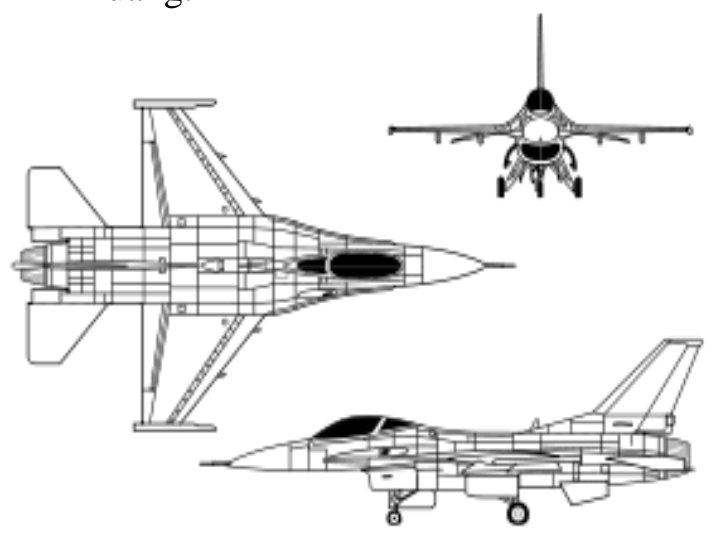

Gambar 9

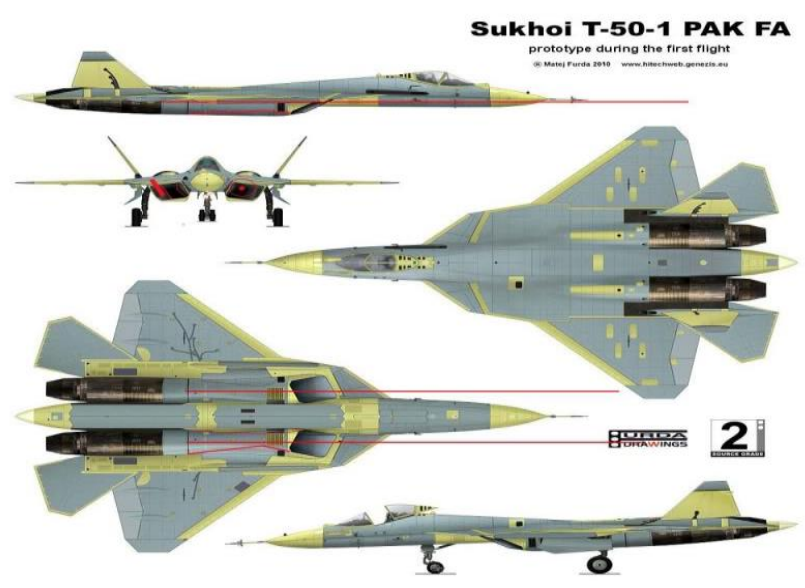

Gambar 10

5) Untuk bagian sayap, F-16 fighting falcon dan Sukhoi PAK-FA T-50 sama-sama menggunakan delta wings, untuk bagian badannya berbeda. Badan F-16 pesawat dibentuk dari sudut-sudut yang beragam, 
sedangkan Sukhoi belended wing body dengan sudut yang beragam seperti di leading edge extension, leading edge sayap, HTP dan VTP. Bentuk sayap yang menyatu dengan badan pesawat (fuselage) disebut dengan blended wing body. Permukaan pesawat terlihat lebih smooth tanpa banyak lekukan yang diakibatkan karena bentuk sayap dan badan pesawat. Blended wingbody bertujuan untuk memberikan manuver dan aerodinamika yang baik serta mampu mereduksi Radar cross selection. Secara umum pesawat generasi 5 dirancang dengan sudut-sudut yang seragam. Sudut pada leading edge sayap, horizontal tailplane dan vertical tailplane dibuat sama besarnya, tujuannyaadalah agar gelombang atau berkas radar yang dipantulkan tidak saling bertabrakan, sehingga tidak menyebabkan berkas kembali ke transmitter. Konsep ini sesuai dengan low radar cross sections.

6) Untuk bagian ekor pada f-16 fighting falcon masih ada yang menggunakan single VTP dan sebagian HTP belum all moving. Sedangkan pada sukhoi terdapat double VTP dengan pemasangan VTP dimiringkan keluar atau canted out.

7) Pada bagian mesin f-16 fighting falcon beberapa pesawat sudah menggunakan thrust vectoring, dan berkemampuan supercruise. Sedangkan pada sukhoi hampir keseluruhan pesawat telah menggunakan thrust vectoring dan mempunyai kemampuan supercruise. Dengan adanya kemampuan supercruise pada engine, menyebabkan pesawat tempur tersebut dapat terbang pada kecepatan supersonik tanpa menggunakan afterburner. Afterburner merupakan penghasil panas yang tinggi dan mudah ditangkap oleh infrared maupun radar. Oleh karena itu, untuk meminimalkan RCS dan untuk tetap mendapatkan kecepatan yang tinggi untuk mengejar atau menghindar lawan, maka pesawat tempur perlu menerapkan kemampuan supercruise. Teknologi supercruise diterapkan untuk menghasilkan kecepatan yang besar dengan bahan bakar yang tidak terlalu banyak, sehingga dapat menghemat konsumsi bahan bakar.

8) Dari segi persenjataan, perbedaan yang menonjol pada pesawat tempur f-16 dan sukhoi adalah peletakan senjatanya. F-16 meletakkan persenjataannya pada hardpoint yang terpasang di luar, sedangkan pada sukhoi semua senjata diletakkan di dalam fuselage, atau yang disebut dengan internal weapon. Pemasangan internal weapon baydimaksudkan untuk mengurangi radar cross section.

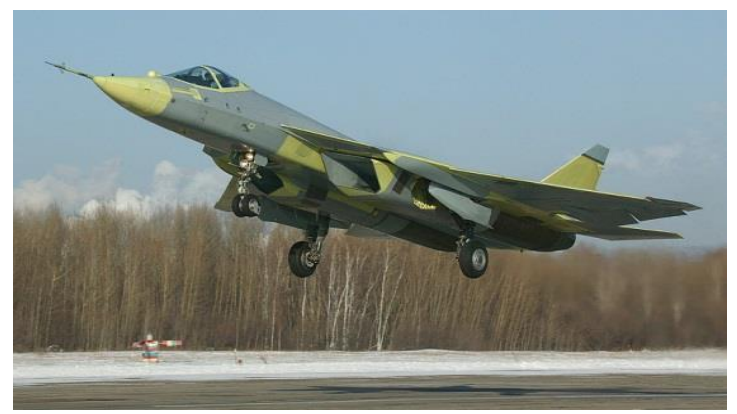

Gambar 11

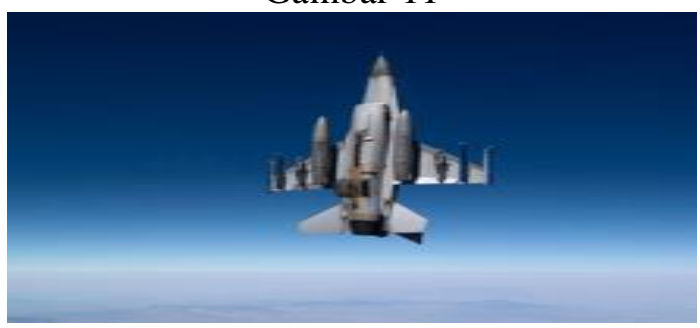

Gambar 12

\section{Simpulan}

Jadi, berdasarkan penelitian yang kita peroleh bahwa dalam pesawat tempur F-16 Fighting Falcon masih banyak kekurangan dari segi badan, ekor, mesin, sayap, persnjataan, duct patch air inlet dan canard. Kekurangan-kekurangan dalam pesawat F-16 Fighting Falcon disempurnakan di generasi ke 5 khususnya di Sukhoi PAK-FA T-50. Tetapi dalam Sukhoi PAK-FA T-50 ini tidak dibilang sempurna total, dikarenakan masih memiliki kekurangan, namun kekurangan tersebut lebih baik dibandingkan dengan F-16 Fighting Falcon.

\section{Daftar Pustaka}

Liu J.,2014," A numerical model for bird strike on sidewall structure of an aircraft nose", Chinese Journal of Aeronautic

Ika S.,2016," Kajian konfigurasi pesawat tempur generasi 4 dan generasi 5, SENATIK Yogyakarta

Larasmoyo N., 2008," Studi Komparasi Karakter Bentuk Estetik Desain Pesawat Tempur F16 dan SU-27", Jurnal Teknik ITB 